\title{
Importance of physical vs. chemical interactions in surface shear rheology
}

\author{
Peter A. Wierenga ${ }^{\mathrm{a}, \mathrm{b}, *}$, Hans Kosters ${ }^{\mathrm{c}}$, Maarten R. Egmond ${ }^{\mathrm{d}}$, \\ Alphons G.J. Voragen ${ }^{\mathrm{b}}$, Harmen H.J. de Jongh ${ }^{\mathrm{a}, \mathrm{e}}$ \\ ${ }^{\text {a }}$ Wageningen Centre for Food Sciences, P.O. Box 557, Diedenweg 20, 6700 AN, Wageningen, The Netherlands \\ ${ }^{\mathrm{b}}$ Wageningen University and Research Centre, Wageningen, The Netherlands \\ ${ }^{c}$ NIZO Food Research, Ede, The Netherlands \\ d Utrecht University, Utrecht, The Netherlands \\ e TNO Quality of Life, Zeist, The Netherlands
}

Available online 27 January 2006

\begin{abstract}
The stability of adsorbed protein layers against deformation has in literature been attributed to the formation of a continuous gel-like network. This hypothesis is mostly based on measurements of the increase of the surface shear elasticity with time. For several proteins this increase has been attributed to the formation of intermolecular disulfide bridges between adsorbed proteins. However, according to an alternative model the shear elasticity results from the low mobility of the densely packed proteins. To contribute to this discussion, the actual role of disulfide bridges in interfacial layers is studied. Ovalbumin was thiolated with $S$-acetylmercaptosuccinic anhydride ( $S$-AMSA), followed by removal of the acetylblock on the sulphur atom, resulting in respectively blocked (SX) and deblocked (SH) ovalbumin variants. This allows comparison of proteins with identical amino acid sequence and similar globular packing and charge distribution, but different chemical reactivity. The presence and reactivity of the introduced, deblocked sulfhydryl groups were confirmed using the sulfhydryl-disulfide exchange index (SEI). Despite the reactivity of the introduced sulfhydryl groups measured in solution, no increase in the surface shear elasticity could be detected with increasing reactivity. This indicates that physical rather than chemical interactions determine the surface shear behaviour. Further experiments were performed in bulk solution to study the conditions needed to induce covalent aggregate formation. From these studies it was found that mere concentration of proteins (to $200 \mathrm{mg} / \mathrm{mL}$, equivalent to a surface concentration of around $2 \mathrm{mg} / \mathrm{m}^{2}$ ) is not sufficient to induce significant aggregation to form a continuous network. In view of these results, it was concluded that the adsorbed layer should not be considered a gelled network of aggregated material (in analogy with three-dimensional gels formed from heating protein solutions). Rather, it would appear that the adsorbed proteins form a highly packed system of proteins with net-repulsive interactions.
\end{abstract}

(C) 2005 Elsevier B.V. All rights reserved.

Keywords: Ovalbumin; Chemical modification; Thiolation; Air-water interface; Surface rheology

\section{Contents}

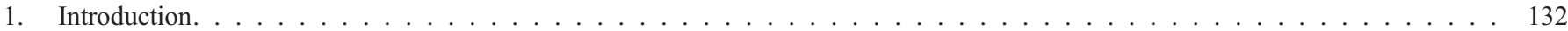

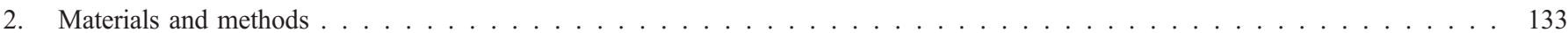

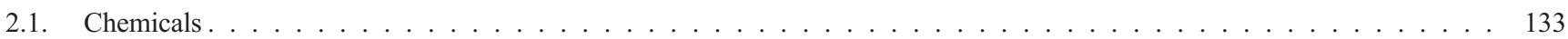

2.2. Introduction of sulfhydryl groups into ovalbumin . . . . . . . . . . . . . . . . . . . 133

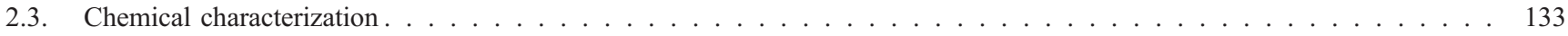

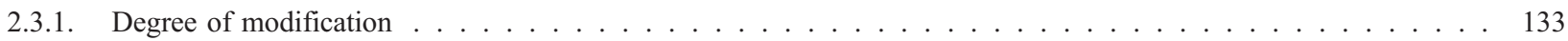

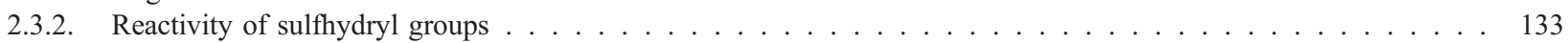

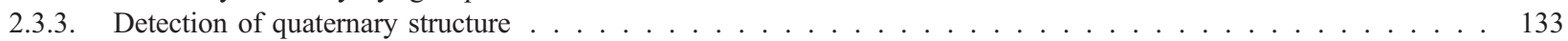

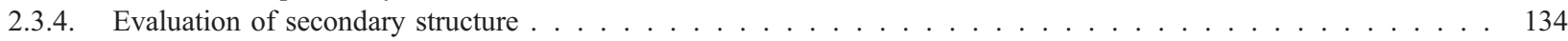

\footnotetext{
* Corresponding author. Wageningen Centre for Food Sciences, P.O. Box 557, Diedenweg 20, 6700 AN, Wageningen, The Netherlands. Tel.: +31 317485440 ; fax: +31317484893 .

E-mail address: peter.wierenga@wur.nl (P.A. Wierenga).
} 


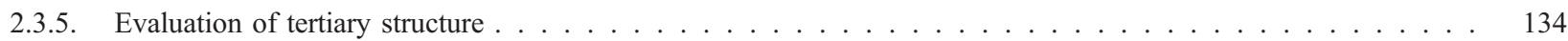

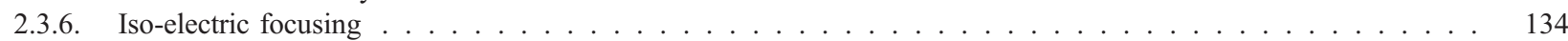

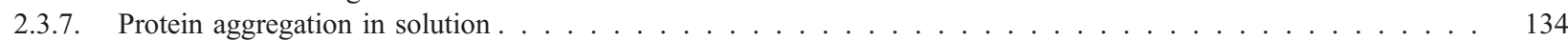

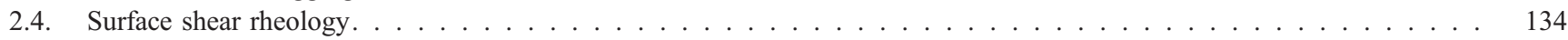

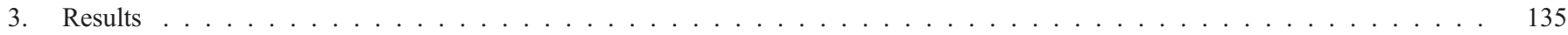

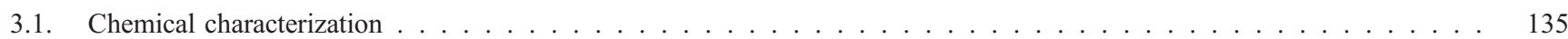

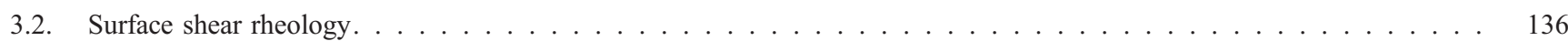

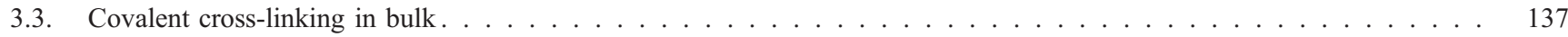

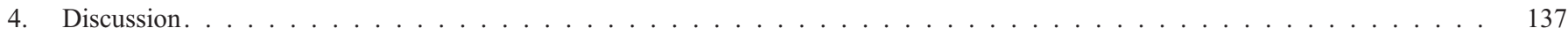

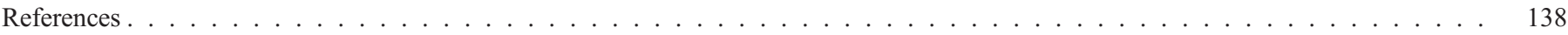

\section{Introduction}

Proteins and low-molecular weight (LMW) surfactants are both known for their ability to form interfacial layers that stabilise foams and emulsions. However, the mechanisms by which they stabilise the interface have been mentioned to be fundamentally different [1,2]. The LMW surfactants are able to freely diffuse at the interface, thereby counteracting a surface pressure gradient across the interface. This is known as the Gibbs-Marangoni effect. For proteins the lateral surface diffusion in the saturated surface layer is found to be much smaller [3]. In this case the stabilization proceeds via a different mechanism, which some authors have suggested to be related to the formation of a continuous network [4,5]. This network would result in a mechanical force resisting deformation of the interface, the elastic modulus. The evidence for the existence of such a network has often been taken from surface shear rheological experiments. These experiments typically use a Couette type (or: concentric cylinders) geometry comparable to that used for the study of gelation in bulk systems. The technique was discussed thoroughly in 1979 by Izmailova [6] and more recently by Bos and van Vliet [1]. Although multiple articles have been published on the surface shear behaviour of protein layers [7-16] a quantitative relationship of this behaviour to a fundamental parameter such as the adsorbed amount is still lacking [17]. One reason for this might be that the interpretation of results from these measurements is not unambiguous. Several authors argue that the adsorbed protein layer is gelled, resulting in a network of highly interacting particles and that as such the rheological behaviour should be interpreted in analogy to the three dimensional equivalent (of heat set protein gels) $[7,12,18-$ 21]. This view is supported by observations of visibly coagulated layers of proteins as described by Macritchie and Owens [22], even though these authors find that coagulation of a protein monolayer occurs only after the surface pressure is increased to higher values than those found for equilibrium spreading pressure of monomeric compounds. Furthermore, Izmailova [6] mentions that formation of macroscopic films with folds and wrinkles is only described in cases of compressed layers, heated solutions and certain interfaces between water and hydrocarbons.

An alternative view, shared by several authors, states that the surface shear behaviour of adsorbed protein layers is the result of the dense packing of loose proteins [17,23,24]. This concept seems to be able to account for observations that the shear elasticity only increases once a certain concentration of adsorbed particles is reached $[6,11]$, and that proteins are displaced from the interface relatively quickly by LMW surfactants [25-27].

If one wants to describe the interfacial behaviour of adsorbed proteins in all its complexity, it is necessary to distinguish between the two described conceptual models. One important difference between the two descriptions of the interfacial layer is the role of covalent interactions. In three-dimensional gels that are formed by heating protein solutions the formation of intermolecular disulfide bonds has been shown to increase the gel strength as measured by the elastic modulus [28]. This observation has also been confirmed for gels formed by acidifying dispersions of pre-aggregated proteins [29-31]. Several authors have suggested that intermolecular disulfide bonds will also be formed between adsorbed proteins if the adsorbed layer is in a gelled state [5,20,32,33]. However, since the cysteine residues are typically located in the interior of the protein and are not readily accessible for the formation of intermolecular bonds, the proteins would need to partially unfold at the interface to expose these residues, as discussed by Damodaran and Anand [5]. In the studies by Damodaran and Anand [5] and Dickinson and Matsumura [33] it was shown that after emulsification there was some polymerisation of $\beta$ lactoglobulin, but the surface shear elasticity was not determined. Other authors used chemical modification of proteins to introduce sulfhydryl groups [34-36]. Their results show that the introduction of sulfhydryl groups itself did not improve the foam formation or stability.

To contribute to the above-mentioned discussion on the nature of adsorbed protein layers, the surface shear behaviour of chemically modified variants of ovalbumin is measured. Using the specific reactivity of $S$-acetylmercaptosuccinic anhydride ( $S$-AMSA) towards the free amino groups of ovalbumin, groups with an acetylated sulphur atom can be introduced at the protein surface. Ovalbumin was chosen, since it was previously found that the protein structural integrity was not affected by mild modification of the lysine groups [37]. The acetyl block can be removed by hydroxylamine, yielding free sulfhydryl groups. Ovalbumin is a $42 \mathrm{kDa}$ glycosylated and phosphorylated protein, containing one disulfide bridge and four free sulfhydryl groups, but these are all located in the 
interior of the protein. After chemical modification and deblocking, reactive sulfhydryl groups are present on the exterior of the protein, thus easily available for the formation of disulfide bridges. By combining the investigation of the chemical properties of the modified proteins and the rheological properties of the adsorbed protein layers, we aim to provide a better understanding of the nature of the interfacial layer and the role of chemical interactions in this layer.

\section{Materials and methods}

\subsection{Chemicals}

$S$-Acetylmercaptosuccinic anhydride (S-AMSA), Orthophthaldialdehyde (OPA), 2-Ethyl-5-phenylisoxazolium-3'-sulfonate (Woodward's reagent $\mathrm{K}$ ) and 2-( $\mathrm{N}$-morpholino)-ethanesulfonic acid (MES) buffer were obtained from Sigma-Aldrich. $\mathrm{N}, \mathrm{N}$-dimethyl-2-mercaptoethyl-ammoniumchloride (DMA) and di-sodiumtetraborate decahydrate (Borax) were purchased from Merck. Sodiumdodecylsulfate (SDS) was from Serva. All chemicals used were of analytical grade.

\subsection{Introduction of sulfhydryl groups into ovalbumin}

Chicken egg ovalbumin was purified (>98\%) as described previously [37]. Primary amino groups in ovalbumin were thiolated essentially as described by Klotz [38]. In this method $S$-acetylmercaptosuccinic anhydride ( $S$-AMSA) is covalently linked to lysine residues on the protein surface. The modification was performed as follows: $200 \mathrm{~mL}$ of a $25 \mathrm{mg} / \mathrm{mL}$ ovalbumin $(0.55 \mathrm{mM})$ solution in demineralized water was adjusted to $\mathrm{pH} 8.0$ by the addition of $1 \mathrm{M} \mathrm{NaOH}$ using a $\mathrm{pH}-$ stat titration equipment (Metrohm) at room temperature. The reagent ( $S$-AMSA) was added to the protein solution in small aliquots, while the $\mathrm{pH}$ was kept at $8.0( \pm 0.1)$ by the addition of $1 \mathrm{M} \mathrm{NaOH}$ using the pH-stat apparatus. Two batches of modified ovalbumin were prepared by a total addition of 28.5 and $97.5 \mathrm{mg} S$-AMSA respectively to obtain a low and a medium degree of modification. After addition, the solution was stirred for another $30 \mathrm{~min}$., followed by extensive dialysis against demineralized water at $4{ }^{\circ} \mathrm{C}$. After dialysis each batch was separated into two fractions. To one fraction, $125 \mathrm{~mL} 0.01$ $\mathrm{M}$ hydroxylamine ( $\mathrm{pH}$ 7.3) was added, to remove the acetyl blocks. To the other fraction $125 \mathrm{~mL}$ distilled water was added to keep concentrations in both solutions equal. The deblocked fraction was then dialyzed against distilled water; both samples were frozen, but not freeze-dried in order to avoid oxidation of the free sulfhydryl groups. The material was stored at $-20^{\circ} \mathrm{C}$ until use.

\subsection{Chemical characterization}

\subsubsection{Degree of modification}

The total number of active sulfhydryl groups in nonmodified, blocked and deblocked ovalbumin was determined using the Ellmann protocol [39]. The reagent, 5,5'-dithiobis(2nitrobenzoic acid) (DTNB), reacts with free thiol groups of the protein. The reagent solution was prepared by dissolving $4.8 \mathrm{mg}$ DTNB in $1.0 \mathrm{~mL}, 10 \mathrm{mM}$ Tris- $\mathrm{HCl}$ buffer $(\mathrm{pH} 8.0$ and $2 \%$ SDS) and subsequent addition of $2.5 \mathrm{~mL}$ Tris $-\mathrm{HCl}$ buffer $(10 \mathrm{mM}, \mathrm{pH} 8.0) .50 \mu \mathrm{L}$ DTNB solution was added to $250 \mu \mathrm{L} 5 \mathrm{mg} / \mathrm{mL}$ protein solution. The solution was mixed and incubated for $20 \mathrm{~min}$ at $25^{\circ} \mathrm{C}$; then the absorbance was measured at $412 \mathrm{~nm}$. The calibration curve, obtained by using various dilutions of a $0.50 \mathrm{mM}$ cysteine solution, provided an extinction coefficient for the reduced conjugate of $13425 \mathrm{M}^{-1} \mathrm{~cm}^{-1}$.

\subsubsection{Reactivity of sulfhydryl groups}

The chemical reactivity of the blocked and deblocked proteins was measured using the sulfhydryl-disulphide exchange index (SEI) as described by Owusu-Arpenten et al. [40]. The method determines both the number of available $-\mathrm{SH}$ groups and the reactivity of these groups. The method is based on the reaction between 2,2'-dipyridyldisulphide (PDS) and a free $-\mathrm{SH}$ group. The formation of the reaction product (2-thiopyridine; 2-TP) can be followed in time by measuring the absorbance at $343 \mathrm{~nm}$. A stock solution of PDS was prepared by dissolving $40 \mathrm{mg}$ PDS in $40 \mathrm{~mL}$ phosphate buffer $(10 \mathrm{mM} \mathrm{pH} 7.0)$ and stirring for $3 \mathrm{~h}$ at $20^{\circ} \mathrm{C}$. Then the solution was filtered over a $0.45 \mu \mathrm{m}$ filter and the concentration of PDS was determined at $281 \mathrm{~nm}$, using a molar extinction coefficient of $9730 \mathrm{M}^{-1} \mathrm{~cm}^{-1}$ [40]. For measurements the stock was diluted to $5 \cdot 10^{-5} \mathrm{M} ; 2.7 \mathrm{~mL}$ of this solution was added to a cuvette and the absorbance at 343 was measured. Then $0.3 \mathrm{~mL}$ of sample solution was added and the adsorbance at $343 \mathrm{~nm}$ followed in time. Sample solutions used were $10 \mathrm{mg} / \mathrm{mL}$ protein (in $10 \mathrm{mM}$ phosphate buffer, $\mathrm{pH}$ 7.0); Glutathion $(0.1 \mathrm{mg} / \mathrm{mL}$ in $0.01 \mathrm{~N} \mathrm{HCl})$ was used for calibration. The total number of reactive - $\mathrm{SH}$ groups was calculated from the plateau value of the adsorbance (using a molar extinction coefficient of $\left.7076 \mathrm{M}^{-1} \mathrm{~cm}^{-1}\right)$ [40]. The rate constant $\left(k_{-\mathrm{SH}}\right)$ of this second-order reaction was calculated from the slope of the graph of the right-hand side of Eq. (1) against time.

$$
k_{-\mathrm{SH}} * t=\frac{1}{\left([\mathrm{PDS}]_{0}-[-\mathrm{SH}]_{0}\right) * \ln \frac{\left([\mathrm{PDS}]_{0}-[2-\mathrm{TP}]\right)[-\mathrm{SH}]_{0}}{\left([-\mathrm{SH}]_{0}-[2-\mathrm{TP}]\right)[\mathrm{PDS}]_{0}}}
$$

When this rate constant is divided by the rate constant of glutathion, a standardized value called the SEI index is obtained; $\mathrm{SEI}=\left(k_{-\mathrm{SH}} / k_{\text {glutathion }}\right) * 100 \%$.

\subsubsection{Detection of quaternary structure}

Size exclusion chromatography (SEC) was used to study the aggregation state of the proteins. SEC was carried out on a Superdex S200 HR column (Pharmacia Biotech) with a bed volume of $24 \mathrm{~mL}$. The column was equilibrated and run with $10 \mathrm{mM}$ phosphate-buffer $\mathrm{pH} 7.0$ and $50 \mathrm{mM} \mathrm{NaCl}$ at $20{ }^{\circ} \mathrm{C}$. The sample ( $200 \mu \mathrm{L}, 5 \mathrm{mg} / \mathrm{mL}$ in the same buffer) was applied to the column and the flow-rate was set to $0.4 \mathrm{~mL} / \mathrm{min}$; detection took place at $280 \mathrm{~nm}$. 


\subsubsection{Evaluation of secondary structure}

Far-UV circular dichroism (CD) spectra of $0.1 \mathrm{mg} / \mathrm{mL}$ protein solutions in $10 \mathrm{mM}$ phosphate buffer $(\mathrm{pH}$ 7.0) were recorded at $20{ }^{\circ} \mathrm{C}$ in the range from 190 to $260 \mathrm{~nm}$ with a spectral resolution of $0.2 \mathrm{~nm}$, on a Jasco J715-spectropolarimeter. The scan speed was $100 \mathrm{~nm} / \mathrm{min}$ and the response time was $0.125 \mathrm{~s}$ with a bandwidth of $1 \mathrm{~nm}$. Quartz cells with an optical path of $0.1 \mathrm{~cm}$ were used. Typically, 16 scans were accumulated and averaged. The spectra were corrected for the corresponding protein-free sample.

\subsubsection{Evaluation of tertiary structure}

The intrinsic fluorescence of the tryptophan and tyrosine residues of $0.1 \mathrm{mg} / \mathrm{mL}$ protein solutions in $10 \mathrm{mM}$ phosphate buffer $(\mathrm{pH} 7.0)$ were measured on a Perkin Elmer Luminescence Spectrometer LS 50 B. The excitation and emission slits were set at $5 \mathrm{~nm}$. The excitation wavelength was 295 or 274 $\mathrm{nm}$, the excitation maxima of tryptophan and tyrosine respectively. The emission spectra were recorded from 300 to $450 \mathrm{~nm}$ with a scan speed of $120 \mathrm{~nm} / \mathrm{min}$. Each spectrum was the average of two scans and corrected for a protein-free sample.

\subsubsection{Iso-electric focusing}

The iso-electric points (IEP) of non-modified and modified ovalbumin variants were determined using the Phast System (Pharmacia). Ready to use PhastGel IEF 3-9 gels were used, which were stained with Coomassie brilliant blue. A calibration kit from Pharmacia was used with proteins that have isoelectric points ranging from 3.5 to 9.3 .

\subsubsection{Protein aggregation in solution}

The chemical reactivity of the modified ovalbumin variants in bulk solution was tested under similar conditions as experienced at the interface by concentrating protein solutions to final concentrations of 100 or $200 \mathrm{mg} / \mathrm{mL}$ (using Centriprep centrifugal filtration units from Millipore). Further experiments were performed by heating $0.1 \mathrm{mg} / \mathrm{mL}$ protein solutions at $90{ }^{\circ} \mathrm{C}$ for $30 \mathrm{~min}$, or by addition of ferricyanide. Any aggregation induced by these treatments was analysed with sodium dodecyl sulfate polyacrylamide gel electrophoresis (SDS-PAGE), SDS-PAGE 8-25 gradient gels (Pharmacia) were run on a Phast-System (Pharmacia). Samples were dissolved in sample buffer, containing $62.5 \mathrm{mM}$ Tris $-\mathrm{HCl}$ (pH 6.8), 1.25\% SDS, 5\% glycerol, $0.00125 \%$ bromophenol blue in the presence or absence of $1.25 \% \beta$-mercaptoethanol, and heated for $10 \mathrm{~min}$ at $100{ }^{\circ} \mathrm{C}$ before analysis. Gels were stained with Coomassie brilliant blue. A calibration kit with low molecular mass markers ranging from 14 to $94 \mathrm{kDa}$ from Pharmacia was used.

\subsection{Surface shear rheology}

To study interfacial shear properties of adsorbed protein layers a Couette-type surface shear rheometer was used as described by Martin et al. [41]. The apparatus is schematically drawn in Fig. 1. First, $279 \mathrm{~mL}$ buffer $(10 \mathrm{mM}$ phosphate, $\mathrm{pH}$ 7.0 , containing $300 \mathrm{mM} \mathrm{NaCl}$ ) was filtered over a $0.2 \mu \mathrm{m}$ filter and then placed in the trough. A concentrated protein solution $(4 \mathrm{~mL})$ was injected under the interface using a syringe, to obtain a final protein concentration of $0.1 \mathrm{mg} / \mathrm{mL}$. A stainless steel biconical disk (diameter $30 \mathrm{~mm}$ ) was suspended from a torsion wire of $0.15 \mathrm{~mm}$ and placed in such a way that the disc edge was exactly at the air-water interface. The solution was left to adsorb and equilibrate for $22 \mathrm{~h}$ while the surface tension was measured with a Wilhelmy plate (perimeter $18.1 \mathrm{~mm}$ ) suspended from a NIMA tensiometer as illustrated in Fig. 1.

In replicate measurements with and without the Wilhelmy plate at the interface it was found that the presence of the plate

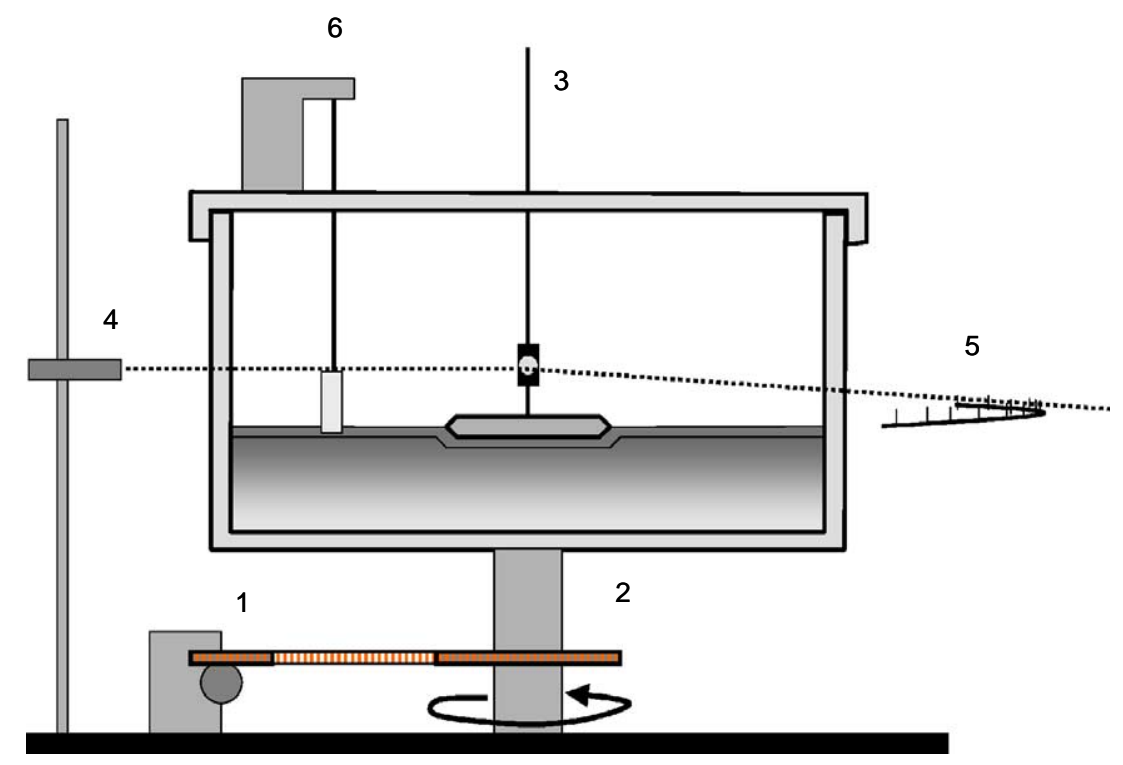

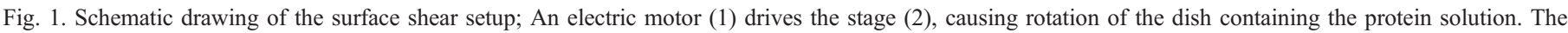

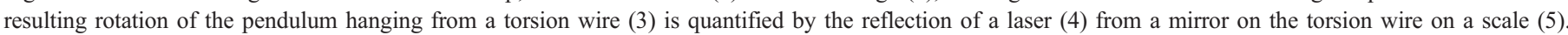
Simultaneously the surface pressure can be measured by a Wilhelmy plate connected to a NIMA tensiometer (6) mounted on the cover of the dish. 


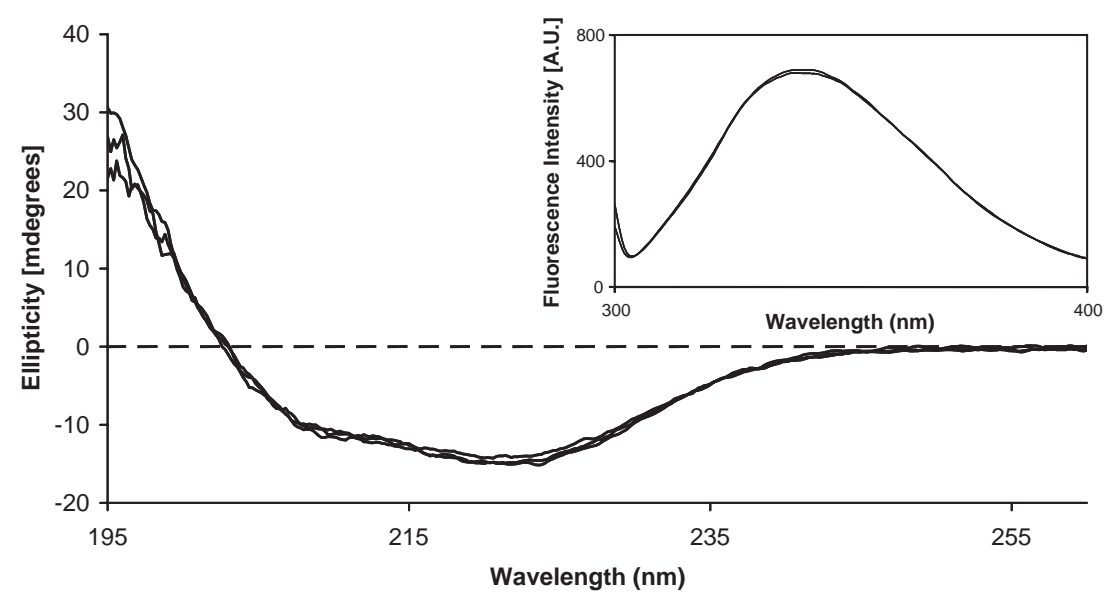

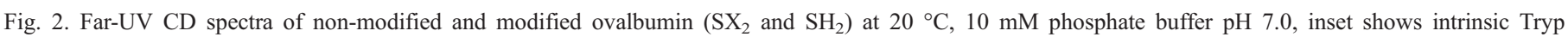
fluorescence of the same samples in the same buffer.

did not affect the results from the surface shear measurements. Stress-strain curves were made as a function of time by rotating the sample dish at a fixed rate during $30 \mathrm{~min}$. The stress acting on the inner disc $(\sigma[\mathrm{mN} / \mathrm{m}])$ resulted in rotation of this disc that was quantified by reading the reflection of a laser beam from a mirror on top of the inner disk on a circular scale with a radius of $600 \mathrm{~mm}$. Assuming homogenous deformation of the surface layer the strain $(\gamma[-])$ applied can be calculated by Eq. (2) [42]:

$\gamma=\frac{2 R_{\mathrm{o}}^{2}}{\left(R_{\mathrm{o}}^{2}-R_{\mathrm{i}}^{2}\right)} \cdot\left(\Theta_{\mathrm{o}}-\Theta_{\mathrm{i}}\right)$

Where $R_{\mathrm{i}}$ is the radius [m] and $\Theta_{\mathrm{i}}$ is the rotational displacement [rad] of the inner disc, and $R_{\mathrm{o}}$ and $\theta_{\mathrm{o}}$ are the radius and rotational displacement of the outer dish; $\Theta_{0}$ is given by the angular velocity of the trough and the time $(\omega * \mathrm{t})$ and $\Theta_{\mathrm{i}}$ is measured from the displacement of the reflected laser light on the circular scale divided by two times the radius of the scale. The stress on the interface is calculated from Eq. (3):

$\sigma=\frac{\tau}{2 \pi R_{\mathrm{i}}^{2}}$

with $\tau=K \Theta_{\mathrm{i}}$ as the torque $[\mathrm{Nm}]$ exerted on the disc, and $K$ as the torsion wire constant. The torsion wire constant was determined by measuring the oscillation time with a calibration weight of $75 \mathrm{~g}$, which is close to the weight of the

Table 1

Chemical presence and reactivity of sulphide groups after chemical modification, as measured by Ellman (with and without SDS), and SEI (without SDS)

\begin{tabular}{lllll}
\hline & $\begin{array}{l}\text { Ellman } \\
(-\mathrm{SDS}) \pm 1\end{array}$ & $\begin{array}{l}\text { Ellman } \\
(+\mathrm{SDS}) \pm 1\end{array}$ & $\begin{array}{l}\mathrm{SEI} \pm 0.1 \\
{[\# \mathrm{SH} / \text { protein }]}\end{array}$ & $\begin{array}{l}K_{\mathrm{SEI}} \\
{\left[\mathrm{M}^{-1} \mathrm{~s}^{-1}\right]}\end{array}$ \\
\hline Non-modified & 0 & 4 & 0 & 2.0 \\
$\mathrm{SX}_{1}$ & 0 & 4 & 0 & 1.8 \\
$\mathrm{SX}_{2}$ & 0 & 4 & 0 & 4.2 \\
$\mathrm{SH}_{1}$ & 1 & 5 & 1 & 8.9 \\
$\mathrm{SH}_{2}$ & 2 & 6 & 3 & 33 \\
\hline
\end{tabular}

pendulum disc. Values for the system parameters are: $\omega=1.27 \cdot 10^{-3} \mathrm{~m}, R_{\mathrm{i}}=1.50 \cdot 10^{-2} \mathrm{~m}, R_{\mathrm{o}}=7.25 \cdot 10^{-2} \mathrm{~m}$, $K=1.73 \cdot 10^{-5} \mathrm{~N} \mathrm{~m} \mathrm{rad}{ }^{-1}$, the radius of the scale is $0.6 \mathrm{~m}$. All experiments were performed at $20{ }^{\circ} \mathrm{C}$. Duplicate measurements were performed after thorough cleaning of the trough by starting with new buffer and new injection of the protein solution.

\section{Results}

Chemical modification of ovalbumin with $S$-AMSA as described in the Materials and methods section yielded four variants; two blocked (SX) and two reactive (SH) variants with two degrees of modification (labelled 1 and 2). Sizeexclusion chromatography results showed that all materials used consists of monomeric proteins (results not shown), illustrating that no auto-oxidation of the material had occurred during preparation, storage and handling. Far-UV CD and tryptophan fluorescence spectra from non-modified and the most extremely modified samples as shown in Fig. 2 and inset appear to be identical. This illustrates that no significant changes of the secondary and tertiary structure occurred as a result of the modification.

\subsection{Chemical characterization}

Table 1 shows the results of the chemical characterization of the modified ovalbumin variants. The presence of free $-\mathrm{SH}$ groups was determined using the Ellman determination in the absence and presence of SDS. Without SDS, no sulfhydryl groups were detected for non-modified and blocked proteins. For $\mathrm{SH}_{1}$ and $\mathrm{SH}_{2}$ proteins 1 and 2 groups per protein molecule were detected respectively. In the presence of SDS the proteins are structurally destabilised, and for non-modified ovalbumin all four free SH groups that are present in the primary sequence of ovalbumin are detected. For all modified samples the amount of detected sulfhydryl groups is also increased due to the exposure of the indigenous groups, in the presence of SDS. These results show that (1) the modification as such did not increase the exposure of the indigenous sulfhydryl groups, (2) 


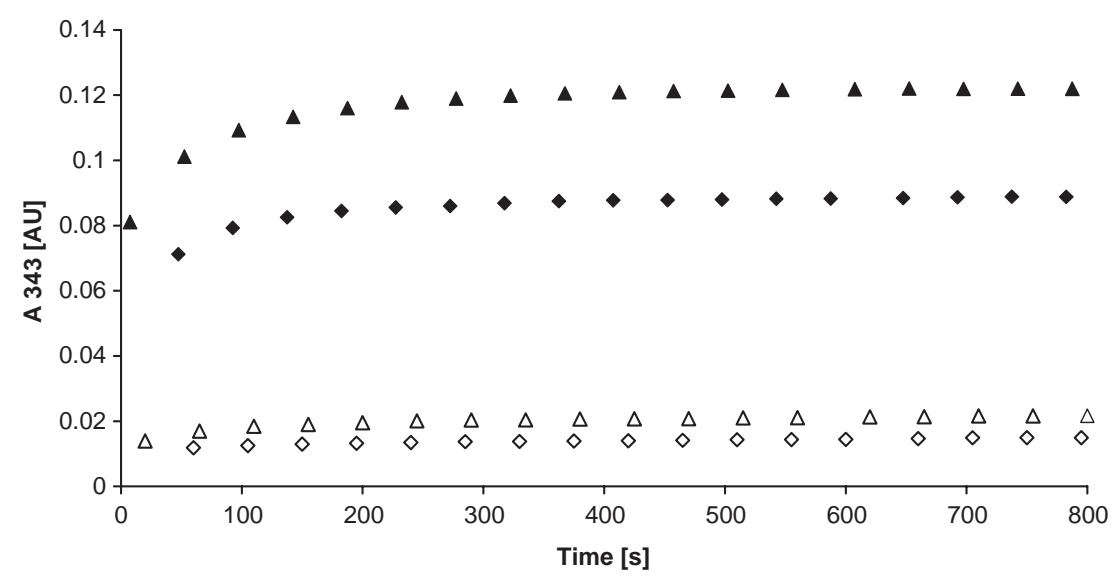

Fig. 3. Fluorescence of $2-\mathrm{TP}$ as a function of time for all variants, $\mathrm{SX}_{1}(\diamond), \mathrm{SX}_{2}(\triangle), \mathrm{SH}_{1}(\diamond), \mathrm{SH}_{2}(\boldsymbol{\Delta})$.

the blocked variants were indeed blocked, and (3) unblocking was successful.

The kinetics of the reaction of sulfhydryl groups with the PDS reagent is shown in Table 1 and in Fig. 3. The amount of $\mathrm{SH}$ groups per protein as measured by $\mathrm{SEI}$ is comparable to that found with Ellman (1 and 3 for $\mathrm{SH}_{1}$ and $\mathrm{SH}_{2}$ respectively). In Fig. 3 it is clearly visible that the deblocked variants have much more reactivity than either the non-modified or blocked variants. The high intensity and rapid increase of the absorbance at $343 \mathrm{~nm}$ found for $\mathrm{SH}_{2}$ in comparison with $\mathrm{SH}_{1}$ must be attributed to the fact that the protein was used in the same protein concentration, leading to higher molar concentrations of sulfhydryl groups. The reaction rate constant for $\mathrm{SH}_{2}$ is found to be three times higher than for $\mathrm{SH}_{1}$. Clearly the sulfhydryl groups that were introduced at the protein surface are reactive.

\subsection{Surface shear rheology}

After determination of the chemical properties of the blocked and deblocked variants of ovalbumin, the samples were used to study the surface shear rheology. Since Martin et al. [41] and Dickinson et al. [43] have shown that surface shear viscosities at air-water interfaces typically reach constant values after $22 \mathrm{~h}$, the measurements were started 22 $\mathrm{h}$ after injecting the protein solution in the shear dish. This time is thus expected to be sufficiently long for adsorption and any rearrangements or cross-linking processes to occur. During this equilibration period the surface pressure was monitored and found to be identical within the experimental error for all samples ( $\Pi$ after $22 \mathrm{~h}$ was $20 \pm 1 \mathrm{mN} / \mathrm{m}$ ). Additional measurement of the surface dilatational modulus (using the conditions as described earlier [44]) showed no significant differences between the samples (results not shown).

The stress at the interface measured by the rotation of the inner disc as a function of the strain applied to the surface is plotted in Fig. 4, and values calculated from these data are given in Table 2. The initial slope of stress versus strain represents Young's modulus for small deformations $\left(E_{\text {young }}=\right.$ $\sigma / \gamma$, data until a strain of 0.8) and varies only little between the samples. The deblocked variants have slightly lower values. At higher deformation the linear, elastic response of stress with strain changes to a more viscous response until at strain values higher than 2 a constant or steady-state stress is measured $\left(\sigma_{\mathrm{ss}}\right)$. Clearly, the presence of sulfhydryl groups on the surface of ovalbumin does not lead to significant increase of any of the parameters describing surface shear; in contrast,

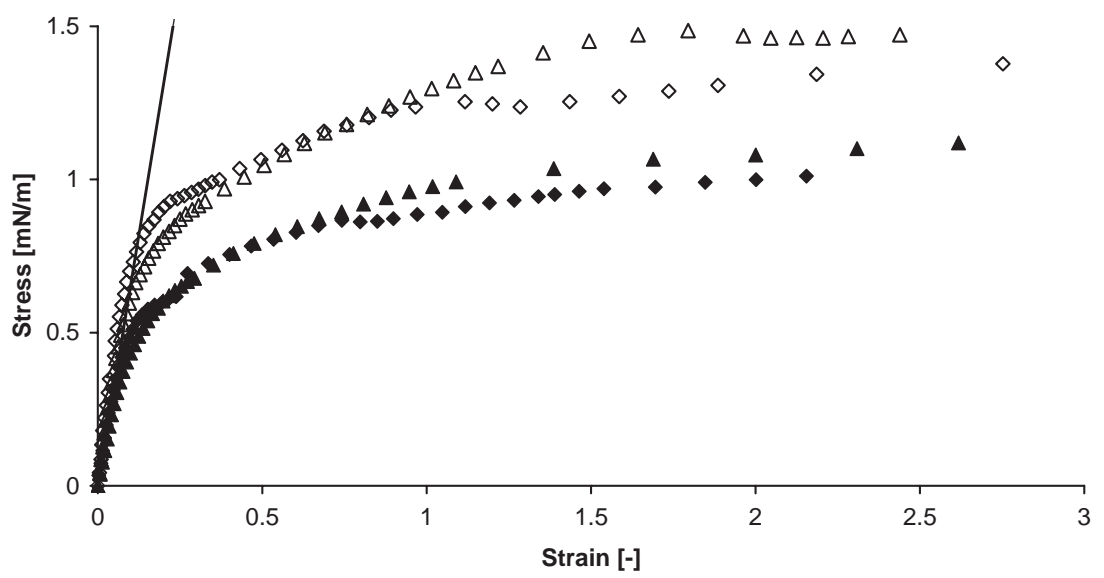

Fig. 4. Surface shear stress plotted against the applied strain for non-modified and modified variants $\left(20^{\circ} \mathrm{C}, 10 \mathrm{mM}\right.$ phosphate buffer $\left.\mathrm{pH} 7.0\right)$; the line shown represents an interface with a constant shear Young modulus of $0.15 \mathrm{mN} / \mathrm{m}$, same symbols as in Fig. 3 . 
Table 2

Surface rheological parameters calculated from the surface shear experiments

\begin{tabular}{lll}
\hline & $E_{\text {young }}( \pm 2)[\mathrm{mN} / \mathrm{m}]$ & $\sigma_{\mathrm{ss}}( \pm 0.06)[\mathrm{mN} / \mathrm{m}]$ \\
\hline $\mathrm{SX}_{1}$ & 9.3 & 1.4 \\
$\mathrm{SX}_{2}$ & 7.3 & 1.4 \\
$\mathrm{SH}_{1}$ & 6.6 & 1.0 \\
$\mathrm{SH}_{2}$ & 5.0 & 1.0 \\
\hline
\end{tabular}

they appear to be lower. For reference values of Young's modulus and $\sigma_{\mathrm{ss}}$ (ranging from $0.0002 \mathrm{mN} / \mathrm{m}$ for $\beta$-casein to $3.2 \mathrm{mN} / \mathrm{m}$ for soy glycinin at $\mathrm{pH} 3$ ) we refer to the work of Martin et al. [20].

\subsection{Covalent cross-linking in bulk}

To test whether the introduced sulfhydryl groups are capable of covalent cross-links between proteins, solutions of each variant (in the same buffer as in the surface shear experiment) were concentrated to concentrations that are comparable to those encountered at the air-water interface [45]: 100 and 200 $\mathrm{mg} / \mathrm{mL}$. Then the samples were left to equilibrate for $22 \mathrm{~h}$, identical to the surface shear experiments. All samples were analysed with SDS-PAGE, with and without addition of $\beta$ mercaptoethanol to distinguish between covalently and noncovalently linked aggregates. The SDS-PAGE gels obtained are shown in Fig. 5A (reducing) and B (non-reducing). Under reducing conditions, only one single band (at $44 \mathrm{kDa}$ ) was visible for all samples, therefore only one example is shown in Fig. 5A. This demonstrates that under these conditions any aggregates formed were completely dissociated.

Under non-reducing conditions, some aggregation $(<5 \%)$ is observed for the $\mathrm{SH}$ variants, but not for the blocked variants (Fig. 5B-1). However, only dimers are formed, and no higher aggregates. From this the picture emerges that under the conditions used, there is little driving force for development of covalent interactions, even at these high protein concentrations. Extensive aggregation could only be obtained by heat treatment. In this case the unfolding of the proteins leads to increased aggregation, even at the low concentrations used. All variants showed similar electrophoresis patterns after heat treatment, of which one is shown in Fig. 5B-2. The increased exposure of the indigenous cysteine residues upon unfolding is sufficient to allow the formation of covalently linked aggre- gates even for non-modified protein; alternatively the addition of the oxidizing agent ferricyanide also induces the formation of covalently linked aggregates. An increase in the amount of aggregates is found for both $\mathrm{SH}_{1}$ and $\mathrm{SH}_{2}$, as compared to the amount formed in the first treatment (Fig. 5B-3). However, the blocked variants showed similar behaviour, indicating that the ferricyanide was also able to remove the blocking acetyl group from the introduced SAMSA groups.

\section{Discussion}

The role of disulfide bridge formation on surface shear behaviour of adsorbed protein layers was investigated using chemically modified ovalbumin variants. The degree of modification was controlled by varying the concentration of the reactant. After modification the introduced $S$-AMSA groups could be deblocked to yield a reactive sulfhydryl group, allowing a comparison of blocked and deblocked variants. In this way, side effects of the modification that have to be accounted for when comparing to non-modified protein are avoided. No significant changes in secondary, tertiary and quaternary structure resulted from the modification (Fig. 2). This is in line with the results obtained with other modifications of ovalbumin in earlier work [37], where typically little or no effects on the protein structure and structural stability are found for low degrees of modification of lysine residues of this protein. Whereas the introduced deblocked sulfhydryl groups were shown to be reactive with both Ellman and SEI (Table 1), they did not result in an increase in surface shear viscosity (Fig. 4). Increasing the protein concentration in bulk solution, to reach essentially identical conditions as at the interface resulted in only little aggregation $(<5 \%$ of the total protein was present as dimer). Apparently, there is not enough attraction between protein molecules to provide temporary associations that allow the formation of short-range chemical reactions to occur.

It is important to note that since the modified groups are at the exterior of the protein, no unfolding at the interface is necessary to expose these groups, as would be the case for unmodified proteins [5]. The small population of dimeric protein that might be formed at the interface (as indicated by the results in Fig. 5B1) will not be sufficient to form a continuous network that would lead to an increase of surface shear elasticity. Rapid formation of higher aggregates could be induced, however, but only by

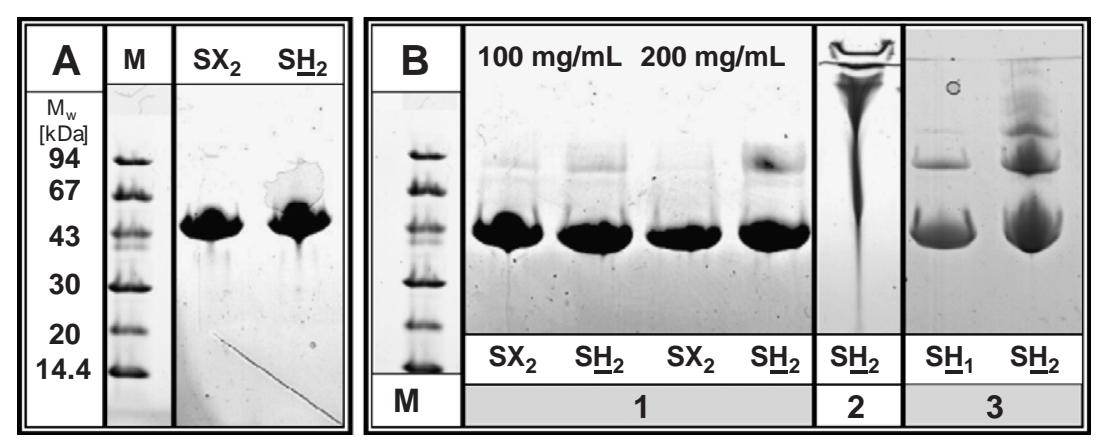

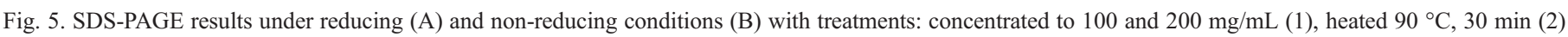
and treated with $5 \mathrm{mM} \mathrm{K}_{3} \mathrm{Fe}(\mathrm{CN})_{6}(3)$, band around $43 \mathrm{kDa}$ indicates the monomeric form of ovalbumin. 
thermal treatment. The thermal treatment results in an unfolding of the protein, increasing the hydrophobic exposure, which increases the tendency to aggregate.

In this respect, the work by Roth et al. [15] provides interesting observations. In this work the surface shear viscosity of adsorbed $\beta$-lactoglobulin was measured during a $24 \mathrm{~h}$ period. After this period the system was heated to 85 or $90^{\circ} \mathrm{C}$, cooled after a certain time and the surface shear viscosity $\left(\eta_{\mathrm{s}}\right)$ of the interface after heat treatment was measured. The surface shear viscosity was found to increase from around 400 to $600-1000$ $\mathrm{mN} / \mathrm{m}$ upon heating. Combined with the observation that heating will cause extensive aggregation and even gelation (especially at the high concentrations at the interface) their results show that before the heat treatment the adsorbed proteins have not formed a continuous network. Faergmand and coworkers found a similar increase of $\eta_{\mathrm{s}}$ after cross-linking adsorbed proteins with transglutaminase [46-48].

These results clearly show that via inducing association between adsorbed proteins, the interfacial layers formed after protein adsorption can be changed in such a way that the shear viscosity is increased. This is a first indication that before treatment associations between adsorbed proteins did not dominate the shear viscosity of adsorbed layers. In addition, covalent interactions are expected to occur if proteins are associated through attractive interactions, based on the evidence from bulk gelation experiments [28-31]. The combination of these findings confirms the notion that adsorbed layers should in general not be described in analogy to three-dimensional gelled systems, but in terms of a system with a dense packing of particles.

A good description of such a model based on packing density rather than covalent interactions can be found in the work of Cicuta and Terentjev and Cicuta et al. [23,24], and Edwards and Wasan [49]. In these models, the shear behaviour is the result of a decreased mobility of the particles due to the close packing. This description can be adjusted to allow for small clusters of aggregates. The occurrence of such small clusters of adsorbed particles was modelled by Ravichandran and Talbot [50] and their effect on shear viscosity has already been described by Eagland [51]. However, even when small aggregates are accounted for, the dense packing description does not presume an order over higher length scales than that of the aggregate, due to formation of a continuous network. The data presented in the present study support this concept.

In conclusion, the inability of chemically reactive proteins at the interface to form covalent cross-links shows that the adsorbed protein layer obtained under relatively mild conditions is not in a 'gelled' state. This is an important observation to improve the understanding of results described in literature on this subject. However, as described by Macritchie and Owens [22] and Izmailova [6], coagulation of adsorbed proteins, leading to the formation of a true gelled or continuous network, can and will occur under specific conditions where stress is applied to the system. Two different processes can be the cause of this transition. Firstly, the repulsion between adsorbed particles can be overcome by thermal treatment as described by Roth et al. [15] and Hellebust at al. [52]. The latter authors found that the protein layer was mainly stabilized by non-covalent forces, although within the network some intermolecular disulfide bonds were detected. The second process is compression of the interface. In several studies it has been shown that if the desorption of particles during the compression is slow enough the particles will be pushed through the intermolecular repulsive barrier [53-56]. This will also result in a gelled state of the interfacial layer. Experimental evidence for the network formation due to compression is found in the article of Hotrum et al. [57]. A further discussion on the transition from a 'densely packed system' to a 'gelled' system is given by de Jongh and Wierenga [58]. During the formation of foam and emulsions, newly formed interfaces are subjected to large deformations. As a result, these interfaces might (partly) consist of a gelled network, which in turn may allow chemical cross-linking between proteins to occur, evidently leading to altered interfacial stabilisation properties.

\section{References}

[1] Bos MA, van Vliet T. Interfacial rheological properties of adsorbed protein layers and surfactants: a review. Adv Colloid Interface Sci 2001;91(3):437-71.

[2] Wilde P, Mackie A, Husband F, Gunning P, Morris V. Proteins and emulsifiers at liquid interfaces. Adv Colloid Interface Sci 2004;108-109: $63-71$.

[3] Blomqvist BR, Ridout MJ, Mackie AR, Warnheim T, Claesson PM, Wilde P. Disruption of viscoelastic beta-lactoglobulin surface layers at the air-water interface by nonionic polymeric surfactants. Langmuir 2004; 20:10150-8.

[4] Dickinson E, Murray BS, Stainsby G. Coalescence stability of emulsionsized droplets at a planar oil-water interface and the relationship to protein film surface rheology. J Chem Soc-Faraday Trans I 1988; $84: 871-83$.

[5] Damodaran S, Anand K. Sulfhydryl-disulfide interchange-induced interparticle protein polymerization in whey protein-stabilized emulsions and its relation to emulsion stability. J Agric Food Chem 1997; 45(10):3813-20.

[6] Izmailova VN. Structure formation and rheological properties of proteins and surface-active polymers of interfacial adsorption layers. Progr Surf Membr Sci 1979;13:141-209.

[7] Bantchev GB, Schwartz DK. Surface shear rheology of beta-casein layers at the air/solution interface: formation of a two-dimensional physical gel. Langmuir 2003;19(7):2673-82.

[8] Freer EM, Yim KS, Fuller GG, Radke CJ. Interfacial rheology of globular and flexible proteins at the hexadecane/water interface: comparison of shear and dilatation deformation. J Phys Chem B 2004;108:3835-44.

[9] Freer EM, Yim KS, Fuller GG, Radke CJ. Shear and dilatational relaxation mechanisms of globular and flexible proteins at the hexadecane/ water interface. Langmuir 2004;20:10159-67.

[10] Izmailova VN, Yampolskaya GP. Rheological parameters of protein interfacial layers as a criterion of the transition from stable emulsions to microemulsions. Adv Colloid Interface Sci 2000;88(1-2):99-128.

[11] Kragel J, Grigoriev DO, Makievski AV, Miller R, Fainerman VB, Wilde PJ, et al. Consistency of surface mechanical properties of spread protein layers at the liquid-air interface at different spreading conditions. Colloids Surf B-Biointerfaces 1999;12:391-7.

[12] Murray BS. Interfacial rheology of food emulsifiers and proteins. Curr Opin Colloid Interface Sci 2002;7(5-6):426-31.

[13] Petkov JT, Gurkov TD, Campbell BE, Borwankar RP. Dilatational and shear elasticity of gel-like protein layers on air/water interface. Langmuir 2000;16:3703-11. 
[14] Ridout MJ, Mackie AR, Wilde PJ. Rheology of mixed beta-casein/betalactoglobulin films at the air-water interface. J Agric Food Chem 2004;52(12):3930-7.

[15] Roth S, Murray BS, Dickinson E. Interfacial shear rheology of aged and heat-treated beta-lactoglobulin films: displacement by nonionic surfactant. J Agric Food Chem 2000;48(5):1491-7.

[16] Strange ED, Holsinger VH, Kleyn DH. Rheological properties of thiolated and succinylated caseins. J Agric Food Chem 1996;44(1):54-8.

[17] Sacchetti M, Yu H, Zografi G. Inplane steady shear viscosity of monolayers at the air-water-interface and its dependence on free area. Langmuir 1993;9(8):2168-71.

[18] Clark DC, Dann R, Mackie AR, Mingins J, Pinder AC, Purdy PW, et al. Surface-diffusion in sodium dodecyl sulfate-stabilized thin liquid-films. J Colloid Interface Sci 1990;138:195-206.

[19] Dickinson E. Properties of emulsions stabilized with milk proteins: overview of some recent developments. J Dairy Sci 1997;80(10): 2607-19.

[20] Martin AH, Grolle K, Bos MA, Stuart MA, van Vliet T. Network forming properties of various proteins adsorbed at the air/water interface in relation to foam stability. J Colloid Interface Sci 2002;254:175-83.

[21] Wijmans CM, Dickinson E. Simulation of interfacial shear and dilatational rheology of an adsorbed protein monolayer modeled as a network of spherical particles. Langmuir 1998;14(25):7278-86.

[22] Macritchie F, Owens NF. Interfacial coagulation of proteins. J Colloid Interface Sci 1969;29(1):66-\&.

[23] Cicuta P, Terentjev EM. Viscoelasticity of a protein monolayer from anisotropic surface pressure measurements. Eur Phys J E 2005;16(2): $147-58$.

[24] Cicuta P, Stancik EJ, Fuller GG. Shearing or compressing a soft glass in 2D: time-concentration superposition. Phys Rev Lett 2003;90(23).

[25] Mackie AR, et al. Orogenic displacement in mixed beta-lactoglobulin/ beta-casein films at the air/water interface. Langmuir 2001;17(21): 6593-8.

[26] McClellan SJ, Franses EI. Exclusion of bovine serum albumin from the air/water interface by sodium myristate. Colloids Surf B-Biointerfaces 2003;30(1-2):1-11.

[27] Pugnaloni LA, Dickinson E, Ettelaie R, Mackie AR, Wilde PJ. Competitive adsorption of proteins and low-molecular-weight surfactants: computer simulation and microscopic imaging. Adv Colloid Interface Sci 2004; 107:27-49.

[28] Doi E, Kitabatake N, Hatta H, Koseki T. Relationship of SH-groups to functionality of ovalbumin. J Am Oil Chem Soc 1988;65:496.

[29] Alting AC, Hamer RJ, de Kruif CG, Paques M, Visschers RW. Number of thiol groups rather than the size of the aggregates determines the hardness of cold set whey protein gels. Food Hydrocoll 2003;17:469-79.

[30] Alting AC, Weijers M, De Hoog EHA, van de Pijpekamp AM, Stuart MAC, Hamer RJ, et al. Acid-induced cold gelation of globular proteins: effects of protein aggregate characteristics and disulfide bonding on rheological properties. J Agric Food Chem 2004;52:623-31.

[31] Vasbinder AJ, Alting AC, Visschers RW, de Kruif CG. Texture of acid milk gels: formation of disulfide cross-links during acidification. Int Dairy J 2003;13:29-38.

[32] Kitabatake N, Doi E. Conformational change of hen egg ovalbumin during foam formation detected by 5,5'-dithiobis(2-nitrobenzoic acid). J Agric Food Chem 1987;35(6):953-7.

[33] Dickinson E, Matsumura Y. Time-dependent polymerization of betalactoglobulin through disulfide bonds at the oil-water interface in emulsions. Int J Biol Macromol 1991;13(1):26-30.

[34] Okumura K, Miyake Y, Taguchi H, Shimabayashi Y. Enhanced stability of protein foam due to disulfide bond formation just after foaming. Agric Biol Chem 1989;53:2029-30.

[35] Okumura K, Miyake Y, Taguchi H, Shimabayashi Y. Formation of stable protein foam by intermolecular disulfide cross-linkages in thiolated alphaS1-casein as a model. J Agric Food Chem 1990;38:1303-6.
[36] Murphy MC, Howell NK. Effect of thiolation on the physicochemical and functional-properties of bovine serum-albumin. J Sci Food Agric 1990;53(4):549-58.

[37] Kosters HA, Broersen K, de Groot J, Simons J, Wierenga P, de Jongh HHJ. Chemical processing as a tool to generate ovalbumin variants with changed stability. Biotechnol Bioeng 2003;84:61-70.

[38] Klotz IM. Succinylation. Methods Enzymol 1967;11:576.

[39] Ellman GL. Tissue sulfhydryl groups. Arch Biochem Biophys 1959; $82(1): 70-7$

[40] Owusu-Apenten RK, Chee C, Hwee OP. Evaluation of a sulphydryldisulphide exchange index (SEI) for whey proteins - beta-lactoglobulin and bovine serum albumin. Food Chem 2003;83(4):541-5.

[41] Martin A, Bos M, Stuart MC, van Vliet T. Stress-strain curves of adsorbed protein layers at the air/water interface measured with surface shear rheology. Langmuir 2002;18:1238-43.

[42] Whorlow RW. Rheological techniques - 2nd ed. Ellis Horwood series in physics and its applications, 2nd ed . New York: Ellis Horwood ltd.; 1992.

[43] Dickinson E, Rolfe SE, Dalgleish DG. Surface shear viscometry as a probe of protein-protein interactions in mixed milk protein films adsorbed at the oil-water interface. Int J Biol Macromol 1990;12(3): 189-94.

[44] Wierenga PA, Meinders MBJ, Egmond MR, Voragen AGJ, de Jongh HHJ. Quantitative description of the relation between protein net charge and protein adsorption to air-water interfaces. J Phys Chem B 2005;109: $16946-52$.

[45] Sengupta T, Damodaran S. Lateral phase separation in adsorbed binary protein films at the air-water interface. J Agric Food Chem 2001; 49:3087-91.

[46] Faergemand M, Murray BS. Interfacial dilatational properties of milk proteins cross-linked by transglutaminase. J Agric Food Chem 1998; 46(3):884-90.

[47] Faergemand M, Murray BS, Dickinson E. Cross-linking of milk proteins with transglutaminase at the oil-water interface. J Agric Food Chem 1997;45(7):2514-9.

[48] Faergemand $M$, et al. Cross-linking of adsorbed casein films with transglutaminase. Int Dairy J 1999;9(3-6):343-6.

[49] Edwards DA, Wasan DT. A micromechanical model of linear surface rheological behavior. Chem Eng Sci 1991;46(5-6):1247-57.

[50] Ravichandran S, Talbot J. Mobility of adsorbed proteins: a Brownian dynamics study. Biophys J 2000;78(1):110-20.

[51] Eagland D. Rheological properties of concentrated polymer dispersions. 1. Effects of concentration, particle size, and size distribution upon shear dependence of viscosity. J Colloid Interface Sci 1970;34(2):249-\&.

[52] Hellebust H, Christiansen C, Skotland T. Biochemical-characterization of air-filled albumin microspheres. Biotechnol Appl Biochem 1993;18: $227-37$.

[53] Schwartz H, Harel Y, Efrima S. Surface behavior and buckling of silver interfacial colloid films. Langmuir 2001;17(13):3884-92.

[54] Fenwick NID, Bresme F, Quirke N. Computer simulation of a Langmuir trough experiment carried out on a nanoparticulate array. J Chem Phys 2001;114(16):7274-82

[55] Aveyard R, et al. Structure and collapse of particle monolayers under lateral pressure at the octane/aqueous surfactant solution interface. Langmuir 2000;16(23):8820-8.

[56] Pugnaloni LA, Ettelaie R, Dickinson E. Computer simulation of the microstructure of a nanoparticle monolayer formed under interfacial compression. Langmuir 2004;20(15):6096-9.

[57] Hotrum NE, Stuart MAC, van Vliet T, van Aken GA. Flow and fracture phenomena in adsorbed protein layers at the air/water interface in connection with spreading oil droplets. Langmuir 2003;19:10210-6.

[58] de Jongh HHJ, Wierenga PA. Probing air-water interface protein films: a multi-angle spectroscopic approach. Biospectroscopy in press. 